\title{
Circadian Forced Desynchrony of the Master Clock Leads to Phenotypic Manifestation of Depression in Rats
}

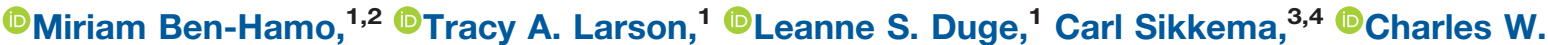
Wilkinson, ${ }^{3,4}{ }^{-}$Horacio 0. de la Iglesia, ${ }^{1,2}$ and ${ }^{\circledR}$ Mónica M. C. González ${ }^{1}$

DOI:http://dx.doi.org/10.1523/ENEURO.0237-16.2016

${ }^{1}$ Department of Biology, ${ }^{2}$ Program in Neuroscience, University of Washington, Seattle, WA 98195, ${ }^{3}$ Geriatric Research, Education and Clinical Center, VA Puget Sound Health Care System, Seattle, WA 98108, and ${ }^{4}$ Department of Psychiatry and Behavioral Sciences, University of Washington, Seattle, WA 98195

\section{Visual Abstract}
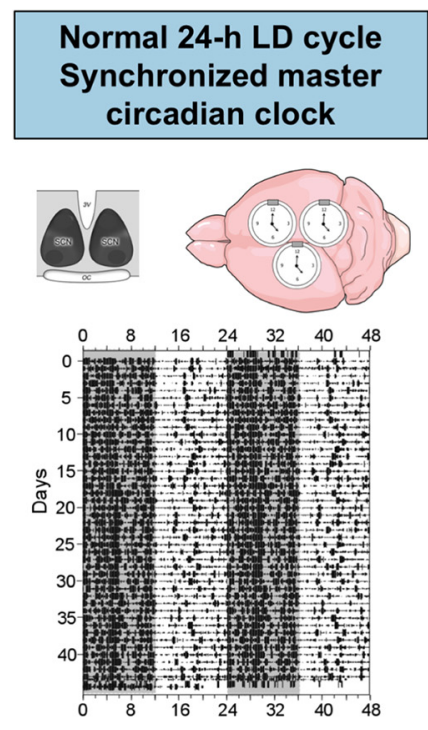

Normal

behavior

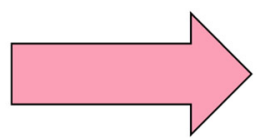

\section{Artificially Short LD cycle \\ Desynchronized master circadian clock}
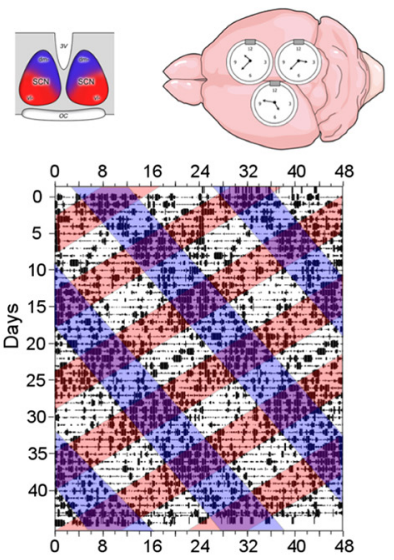

Depressive phenotype in the dark (active) phase

\section{Significance Statement}

Previous studies hypothesized that disruption of the internal coordination of circadian rhythms by the master circadian clock may contribute to the etiology of mood disorders. This hypothesis has not yet been tested in genetically and neurologically intact animal models with impairment of the master clock's ability to maintain circadian internal synchronization. We compared rats exposed to 22-h light-dark cycle, which leads to forced desynchrony of neuronal oscillators within the suprachiasmatic nucleus, to rats exposed to a normal 24-h light-dark cycle. We show that forced desynchrony induces a depressive phenotype that is particularly manifested during the animal's dark (active) phase. Our results demonstrate that prolonged internal misalignment of circadian rhythms may constitute part of the etiology of depression. 
In mammals, a master circadian clock within the suprachiasmatic nucleus (SCN) of the hypothalamus maintains the phase coherence among a wide array of behavioral and physiological circadian rhythms. Affective disorders are typically associated with disruption of this fine-tuned "internal synchronization," but whether this internal misalignment is part of the physiopathology of mood disorders is not clear. To date, depressive-like behavior in animal models has been induced by methods that fail to specifically target the SCN regulation of internal synchronization as the mode to generate depression. In the rat, exposure to a 22-h light-dark cycle (LD22) leads to the uncoupling of two distinct populations of neuronal oscillators within the SCN. This genetically, neurally, and pharmacologically intact animal model represents a unique opportunity to assess the effect of a systematic challenge to the central circadian pacemaker on phenotypic manifestations of mood disorders. We show that LD22 circadian forced desynchrony in rats induces depressive-like phenotypes including anhedonia, sexual dysfunction, and increased immobility in the forced swim test (FST), as well as changes in the levels and turnover rates of monoamines within the prefrontal cortex. Desynchronized rats show increased FST immobility during the dark (active) phase but decreased immobility during the light (rest) phase, suggesting a decrease in the amplitude of the normal daily oscillation in this behavioral manifestation of depression. Our results support the notion that the prolonged internal misalignment of circadian rhythms induced by environmental challenge to the central circadian pacemaker may constitute part of the etiology of depression.

Key words: behavior; circadian rhythms; depression; emotion; rat

\section{Introduction}

In mammals, circadian rhythms are coordinated by a master circadian clock located in the suprachiasmatic nucleus $(\mathrm{SCN})$, where transcriptional and translational feedback loops within single cells oscillate with a period of approximately $24 \mathrm{~h}$; these cells compose a neuronal network that generates robust endogenous circadian oscillations (Colwell, 2011). Direct retinal projections to the $\mathrm{SCN}$ via the retinohypothalamic tract (RHT) assure entrainment of the master clock-as well as the body rhythms it regulates-to the light-dark (LD) cycle (Golombek and Rosenstein, 2010). In this manner, the SCN governs a wide array of behavioral and physiological rhythms including the sleep-wake cycle, body tempera-

Received August 11, 2016; accepted November 28, 2016; First published December 5, 2016.

The authors declare no competing financial interests.

Author contributions: MB-H, TAL, HOD, and MMCG designed research, performed research, analyzed data and wrote the paper. CWW performed research and wrote the paper. LSD and CS performed research.

Supported by HHS, National Institutes of Health [R01MH075016 R01NS094211]; National Science Foundation [IOS0909716]; National Alliance for Research on Schizophrenia and Depression [Young Investigator Award]; Israeli Committee for Higher Education [Postdoctoral Fellowship for Women]; Washington Research Foundation Innovation postdoctoral fellowship in Neuroengineering]; Geriatric Research, Education and Clinical Center, and the Research and Development Service of the VA Puget Sound Health Care System.

Mónica M. C. González's present address is Instituto Ferrero de Neurología y Sueño, Buenos Aires, Argentina.

Tracy A. Larson's present address is Department of Biology, University of Virginia, Charlottesville.

Acknowledgments: We thank Camilo Silva, Jennifer Gile, and Emma Morris for their help with surgeries and animal care.

Correspondence should be addressed to either of the following: Horacio O. de la Iglesia, E-mail: horaciod@uw.edu; or Mónica M. C. González, E-mail: mgonzalez@ifn.com.ar. Horacio O. de la Iglesia, Department of Biology, University of Washington, Seattle, WA 98195-1800, USA. Mónica M. González, Instituto Ferrero de Neurología y Sueño (IFN), Junín 1120-CABA, Argentina.

DOI:http://dx.doi.org/10.1523/ENEURO.0237-16.2016

Copyright ( 92016 Ben-Hamo et al.

This is an open-access article distributed under the terms of the Creative Commons Attribution 4.0 International, which permits unrestricted use, distribution and reproduction in any medium provided that the original work is properly attributed. ture, hormone release, appetite, and cognitive functions (Saper et al., 2005). This regulation is achieved directly or through inputs to both central and peripheral extra-SCN circadian oscillators that locally time tissue-specific processes (Mohawk et al., 2012). Thus, the SCN master clock is responsible for maintaining phase coherence within the complex network of body oscillators and the rhythms they regulate. Disruption of this fine-tuned "internal synchronization" is often associated with both somatic and neuropsychiatric disorders (Takahashi et al., 2008; Wulff et al., 2010; McCarthy and Welsh, 2012; Morris et al., 2012; McClung, 2013).

Numerous lines of evidence support the association between abnormal endogenous circadian rhythms and affective disorders. Patients with affective disorders show disruptions in an array of circadian rhythms including sleep, body temperature rhythm, and hormone release (Boivin, 2000; Wirz-Justice, 2006), suggesting that mood disorders are linked to impairment of the master regulation of circadian rhythms rather than the disruption of isolated rhythmic outputs. Moreover, bright light therapy, sleep deprivation, sleep phase advance, and social rhythm therapy, which are all capable of resetting the phase of the master circadian clock, were shown to be effective in the treatment of affective disorders (Riemann et al., 2002; Frank et al., 2005; Golden et al., 2005; Hemmeter et al., 2010). In addition, the SCN projects directly or through relays to the prefrontal cortex, hippocampus, and amygdala (Leak and Moore, 2001) and trans-synaptically drives the circadian cellular activity of monoaminergic brain regions (Aston-Jones et al., 2001; Luo and Aston-Jones, 2009), all of which are associated with mood regulation. Accordingly, exposure to short photoperiods or constant light can lead to behavioral symptoms of depression in different rodent models (Prendergast and Nelson, 2005; McClung, 2011), and rats exposed to constant darkness for several weeks show apoptosis in mood-related monoaminergic neurons in association with a depressive behavioral phenotype (Gonzalez and Aston-Jones, 2006, 2008). These environ- 
mental light effects were attributed in part to the master circadian clock. Finally, mice with mutated or knockeddown clock genes typically show abnormal affective behavior (Prickaerts et al., 2006; Roybal et al., 2007; Keers et al., 2012). These behavioral effects emerge, at least in part, from the absence of a functional clock within SCN neurons, as region-specific knockdown of the clock gene Bmal1 in the SCN is associated with similar behavioral manifestations of depression (Landgraf et al., 2016).

Taken together, these findings have led to the hypothesis that the disruption of the circadian system and specifically the internal phase coordination of circadian rhythms by the master circadian clock may constitute part of the etiology of mood disorders. Nevertheless, this hypothesis has not yet been tested in genetically and neurologically intact animal models-better concurring with the etiology of affective disorders in humans-with targeted impairment of the master clock's ability to maintain circadian internal synchronization. de la Iglesia et al. (2004) developed a genetically, neurally and pharmacologically intact rat model of "forced desynchrony," in which the mere exposure to a symmetric 22-h light-dark cycle (LD22) leads to the uncoupling of two distinct populations of neuronal oscillators within the SCN: the ventrolateral SCN (vISCN) and the dorsomedial SCN $(\mathrm{dmSCN})$. Forced desynchronized rats present key properties of human forced desynchrony such as the desynchronized circadian regulation of temperature, sleep stages, melatonin, and cortisol (Cambras et al., 2007; Lee et al., 2009; Schwartz et al., 2009; Wotus et al., 2013). The purpose of the present study was to take advantage of the forced desynchronized rat to test the prediction that a systematic challenge to the central circadian pacemaker's ability to maintain the internal synchronization of circadian rhythms will itself cause an altered affective state. We show that forced desynchrony of circadian rhythms in rats induces signature symptoms that characterize depression in animal models including anhedonia, sexual dysfunction, and increased immobility in the forced swim test (FST), as well as changes in the levels and turnover rates of monoamines within the prefrontal cortex (PFC).

\section{Materials and Methods}

\section{Animals and housing}

Adult Wistar male rats (2 months old, Charles River Laboratories, Raleigh, NC) were housed in individual transparent cages with ad libitum access to standard rodent diet (5001, LabDiet, St. Louis, MO) and water. Animals were kept in a ventilated chamber for 9-12 weeks at constant humidity and temperature $\left(21 \pm 1^{\circ} \mathrm{C}\right)$ under a 12:12 LD (12 h light, $12 \mathrm{~h}$ dark) cycle (control group, LD24) or under an 11:11 LD (11 h light, $11 \mathrm{~h}$ dark) cycle (desynchronized group, LD22). Light intensity, as measured inside the individual cages at the level of the rat's eyes, was $64 \pm 11$ lux during the light phase and $<1$ lux dim red light during the dark phase. Animals were individually housed because group housing interferes with desynchrony and the recording of locomotor activity rhythm of each individual. In an effort to minimize stress during the behavioral tests, rats were briefly handled two to four times a week during the dark phase by the same experimenter that performed the behavioral tests. Females were not used for behavioral tests (except for testing male sexual behavior) because the interaction between circadian desynchrony and estrous cycle, which is expected to affect behavioral tests, would require more animals and a different experimental design. The Institutional Animal Care and Use Committee of the University of Washington approved all procedures.

\section{Forced desynchrony}

Desynchrony was assessed by continuous recording of locomotor activity rhythms through crossed infrared beams and analysis with the Sokolove and Bushell (1978) periodogram. Infrared beam breaks were recorded in 10min bins using Clocklab (Actimetrics, Wilmette, IL). After 3 weeks under LD22, two locomotor rhythms emerged with different period lengths, confirmed by Sokolove-Bushel periodogram analysis using El Temps (A. Díez-Noguera; Universidad de Barcelona, Barcelona, Spain; Fig. 1). One rhythm was entrained by the LD cycle and had a period of $22 \mathrm{~h}$ and the other was dissociated from the LD cycle and had a period $>24 \mathrm{~h}(\sim 25 \mathrm{~h})$. Rats that failed to desynchronize ( $20 \%)$ were removed from the study. The two locomotor activity rhythms of desynchronized rats periodically come in phase (aligned days) when the 22- and $\sim 25$-h locomotor activity bouts overlap with each other (Fig. 1; circled A and B), and come out of phase (misaligned days), when one locomotor activity bout starts where the other ends (Fig. 1; circled C and D). During aligned days, both locomotor activity bouts $(\tau=22 \mathrm{~h}$ and $\tau=\sim 25 \mathrm{~h}$ ) occur during the dark phase and both rest bouts during the light phase.

\section{Behavioral tests}

For the behavioral tests, control rats were tested in either the middle of their active phase [zeitgeber time 18 (ZT18), where ZT12 is the time of lights off] or the middle of their rest phase (ZT6). Similarly, desynchronized rats were tested on aligned days in either the middle of their active phase (circled A in Fig. 1) or the middle of their rest phase (circled B in Fig. 1), or on misaligned days in either the middle of the LD22 light phase (circled C in Fig. 1) or the middle of the LD22 dark phase (circled D in Fig. 1). Rats were also weighed to the nearest $0.2 \mathrm{~g}$ (V41PWE1501T; Ohaus, Parsippany, $\mathrm{NJ}$ ) once a week when their cages were changed to assess differences in body weight between groups, as body weight changes have been linked to depression (Shioiri et al., 1993).

We divided rats into three cohorts. One cohort (control: $n=22$; desynchronized: $n=47$ ) was tested in the saccharin preference test (SPT) and sexual behavior test (SBT), allowing a recovery period of at least a week between two sequential tests. A sample of rats from this cohort (control: $n=12$; desynchronized: $n=19$ ) was tested in the open field test (OFT). The second cohort (control: $n=16$; desynchronized: $n=24$ ) underwent a single FST. The third cohort (control: $n=9$; aligned: $n=$ 8) was subjected to a single OFT followed by decapitation and harvesting of brain tissue for chromatographic analysis. The OFT results from this cohort (not shown) were 

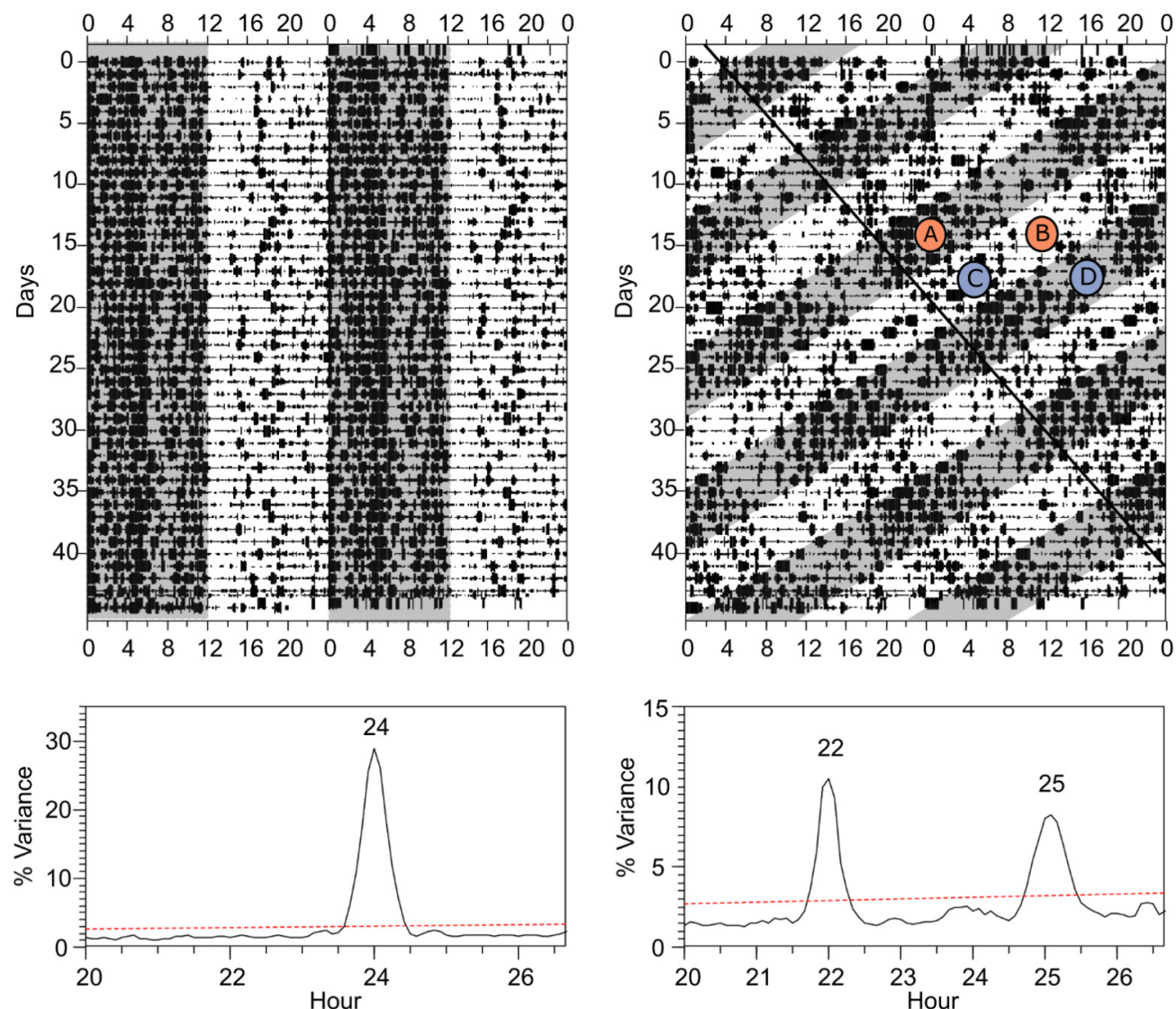

Figure 1. Forced desynchrony of locomotor activity. Top, Double-plotted actograms for locomotor activity of representative rats maintained on symmetric 24-h (left; $12 \mathrm{~h}$ light, $12 \mathrm{~h}$ dark) or 22-h (right; $11 \mathrm{~h}$ light, $11 \mathrm{~h}$ dark) LD cycles. The gray shading indicates lights off. The black line on the LD22 plot indicates the onset of locomotor activity for the LD-dissociated bout of activity. Letters represent phases at which LD22 desynchronized animals were tested. During aligned days, animals were tested in the dark phase $(\boldsymbol{A})$ or the light phase $(\boldsymbol{B})$. During misaligned days, animals were also tested in the light phase $(\boldsymbol{C})$ or the dark phase $(\boldsymbol{D})$. Although all four phases are shown schematically in the same animal, each animal was tested only once at one of these four phases. Bottom, Periodograms of the time series represented in each actogram. Analysis revealed a single statistically significant peak for the LD24 animal and two statistically significant peaks for the LD22 animal. The numbers above the peaks indicate the period of the significant peaks in hours.

similar to those from cohort 1. For chromatography, we used rats only during aligned days because they showed the most pronounced differences in behavioral performance compared with control rats. All of the behavioral tests, with the exception of the SPT that was done in the rats' home cage, were done in a ventilated chamber kept at constant temperature and humidity. Animals were transferred to the behavioral testing room in their home cages. Lighting conditions in the testing chamber were similar to those in the housing chamber at the time of the test: $\sim 60$ lux for animals tested during the light phase and 1 lux red light for animals tested during the dark phase. The latter animals were transported to the behavioral test chamber under darkness.

\section{Saccharin preference test}

To assess anhedonia, rats from both groups were offered two identical bottles, one filled with tap water and the other with $0.1 \%$ saccharin solution in tap water for a period of 8 days. Bottles were weighed daily to $\pm 0.1 \mathrm{~g}$ to track liquid consumption of the animals over a period of $24 \mathrm{~h}$, and the position of the bottles was switched daily (at
15:00, which corresponds to ZT12 for controls, and falls at different time points on the LD cycle of the desynchronized rats) to prevent possible effects of side preference in drinking. We then calculated the proportion of $0.1 \%$ sucrose consumption out of total liquid consumption. For LD24 animals, the data from all 8 days was included. During the 8-day period, each LD22 animal went through one aligned and one misaligned day; only these days were included in the analysis, and days in which the animals were neither aligned nor misaligned were not included.

\section{Open field test}

To assess anxiety, desynchronized and control rats were placed at the lower right corner of a black square Plexiglas arena $(90 \times 90 \times 30 \mathrm{~cm}$; width $\times$ length $\times$ height). Animal movements were monitored for $10 \mathrm{~min}$ using a surveillance video camera (WV-BP334, Panasonic, Osaka, Japan) attached to the ceiling, $2 \mathrm{~m}$ above the center of the arena. We used an open-source automated movement-tracking code that uses Matlab (MathWorks, Natick, MA) as a platform (http://www.seas.upenn.edu/ $\sim$ molneuro/autotyping.html) to calculate the fraction of 
time spent in the perimeters of the arena (Patel et al., 2014), which is a measure of anxiety.

\section{Sexual behavior test}

Sexual dysfunction is reported in $50-60 \%$ of untreated patients with depression (Kennedy et al., 1999; Bonierbale and Tignol, 2003), and sexual inquiry is recommended as an integral component of the medical evaluation (Basson and Schultz, 2007). To assess sexual function, males were placed in a transparent Plexiglas arena $(40 \times 60 \times$ $40 \mathrm{~cm}$; width $\times$ length $\times$ height) covered with a $5-\mathrm{mm}$ layer of bedding (Bed o'Cobs, The Andersons, Maumee, $\mathrm{OH}$ ) and were allowed 5 min to habituate to the arena before a receptive female was introduced. The behavior of the rat pair was monitored with a surveillance camera (WV-BP334, Panasonic) until the first event of ejaculation occurred or for $30 \mathrm{~min}$ if the male did not ejaculate. During this period, we recorded the frequency and timing of three different male behaviors: mounting, intromission, and ejaculation as previously defined by Ågmo (1997). Using this information, we calculated several standard parameters of sexual behavior: latency to ejaculation, latency to mounting, latency to intromission, and copulatory rate, as follows:

$$
\frac{\text { Copulatory rate }}{\text { \# mountings }+ \text { \# intromissions }} \text { (latency to ejaculation - latency to mounting) }
$$

To induce sexual receptiveness, females were anesthetized with isoflurane by inhalation. Their ovaries were removed with a flank incision of about $1.5 \mathrm{~cm}$, and another $1-\mathrm{cm}$ incision to the underlying muscle tissue. The oviduct was ligated with absorbable sutures, and the ovary was then removed. The same procedure was repeated on the opposite side to remove the second ovary. The peritoneum was sutured with absorbable sutures and the skin with wound clips. Females were given at least 7 days of recovery before being used for the behavioral tests. Sexual receptiveness was induced by two injections of $20 \mu \mathrm{g}$ of estradiol suspended in flaxseed oil 48 and 24 $\mathrm{h}$ before the behavioral test and an injection of $1 \mathrm{mg}$ of progesterone suspended in flaxseed oil $4 \mathrm{~h}$ before the behavioral test.

\section{Forced-swim test}

Rats were individually subjected to a unique 5-min FST in a separate room following Gonzalez and Aston-Jones (2008). Briefly, rats provided with a flotation aid were placed for $5 \mathrm{~min}$ in a tank $(38.5 \mathrm{~cm}$ height $\times 30.5 \mathrm{~cm}$ diameter; Instech Laboratories, Plymouth Meeting, PA) with warm water $\left(30^{\circ} \mathrm{C}\right)$. The tank was placed inside a black cylinder to reduce visual stimuli during the test. Rats were briefly handled throughout the 2 weeks before the test. The brief handling, warm water, and flotation aid were used to reduce stress as a confounding factor for the evaluation of a mood-related behavioral phenotype. Under these conditions, Gonzalez and Aston-Jones (2008) demonstrated that a single exposure to the FST can reveal a depressive behavioral phenotype in a single assay. A digital video camera over the tank recorded behaviors during the FST. Immediately after the test, each animal was removed from the water, towel-dried, and returned to its home cage. The water was changed and the cylinder cleaned between rats. Two observers blinded to the experimental conditions scored immobility (when the animal is being completely motionless, with no movements of limb, tail, or head) offline on a video monitor from videotaped images using Behavior Coding 2.18 (David Hurley, University of Washington, Seattle, WA).

\section{High-performance liquid chromatography (HPLC)}

Immediately after the OFT (the only test these animals underwent), LD24 control rats and LD22 aligned rats were moved to an adjacent room with the same lighting conditions of the test, where they were decapitated with a guillotine. The brain was rapidly removed from the skull and placed on filter paper soaked in $0.01 \mathrm{M}$ chilled PBS. A single coronal cut was made across both hemispheres of the brain at bregma $+3.7 \mathrm{~mm}$, and both the left and right PFC regions (Paxinos and Watson, 1998) were dissected with fine scissors. The tissue was placed in a centrifuge tube and quickly frozen on dry ice. Less than 2 min passed from the time of decapitation to the freezing of the prelimbic and cingulate cortex tissue. The tissue was stored at $-80^{\circ} \mathrm{C}$ until processing.

Each tissue sample was sonicated in $0.5 \mathrm{ml}$ of $0.1 \mathrm{M}$ perchloric acid and $2 \mu \mathrm{M}$ ascorbic acid. A $100-\mu \mathrm{l}$ aliquot of the sonicated material was stored at $-70^{\circ} \mathrm{C}$ for protein determination with a Pierce BCA Protein Assay Kit (Thermo Fisher Scientific, Rockford, IL). After centrifugation of the remainder of the sonicated material at 13,000 $\times g$ for $15 \mathrm{~min}$, the supernatant was collected and stored at $-70^{\circ} \mathrm{C}$ for later use. After thawing, $200 \mu \mathrm{l}$ of the supernatant was filtered through a 0.22 Millex GV syringedriven filter and transferred to an autosampler tube before injection. Detection was performed with an ESA Coulochem II electrochemical detector (ESA Laboratories, Chelmsford, MA) with the conditioning cell set at -300 $\mathrm{mV}$, electrode 1 of the analytic cell set at $-90 \mathrm{mV}$, and electrode 2 of the analytic cell set at $350 \mathrm{mV}$, and a Phenomonex reversephase c18 Gemini column $(150 \times 4.6 \mathrm{~mm}, 3 \mu \mathrm{m}, 110 \AA$; Phenomenex, Torrance, CA). The EZChrom Elite chromatography data system (Agilent Technologies, Santa Clara, CA) was used for data reduction. Norepinephrine (NE), 3-methoxy-4hydroxyphenylglycol (MHPG), dopamine (DA), 3,4-dihydroxyphenylacetic acid (DOPAC), serotonin (5-HT), and 5-hydroxyindole acetic acid (5-HIAA) were separated and quantified. Concentrations are expressed as $\mathrm{pg} / \mu \mathrm{g}$ protein.

\section{Statistical analysis}

The changes in body mass and mean locomotor activity of rats from different groups were compared using repeated-measures ANOVA with rat ID as a random factor nested within treatment group. Many behavioral tests are heavily reliant on locomotor activity. To account for this confounding effect, we included mean locomotor activity in the home cage of each rat during the day of the test as a covariate. Whenever locomotor activity did not have a significant effect on behavioral performance, it was excluded from the model, and we report its effect only when 
found significant. Fraction of saccharin consumption was not normally distributed, and therefore we used the nonparametric Kolmogorov-Smirnov test to compare the groups and Bonferroni correction for multiple comparisons. The reported $p$-values are corrected values. Fraction of time spent in perimeter in the OFT, immobility during the FST, copulatory rate, and levels of monoamines in the PFC were all compared between groups and phase using two-way ANOVA. Because a significant number of animals did not display sexual behavior during the test, our data were strongly right skewed. For this reason, we used Kaplan-Meier survival analysis to compare differences in latency to mounting, intromission, and ejaculation between desynchronized and control rats during the dark and light phases.

We also calculated a depression score for rats that were tested on multiple behavioral tests. Because the FST was done on a different cohort of rats, it was not included. Thus, the depression score we calculated for each individual (control: $n=20$, desynchronized: $n=47$ ) was the sum of the standardized (as $z$-values obtained subtracting the mean and dividing by the standard deviation) mounting latency, standardized ejaculation latency, standardized copulatory rate, and standardized saccharin consumption. We multiplied the standardized saccharin consumption and copulatory rate by -1 to make sure that for all behavioral measures, a higher score is indicative of a higher depressive phenotype. Because the depression scores did not distribute normally, we used the Kruskal-Wallis nonparametric test to compare the scores of the three different treatment groups. Finally, we used linear regression analysis to test the relationship between performance in the different behavioral tests and the amplitude of locomotor activity rhythm on the day of the test, calculated as the difference between mean locomotor activity per hour during the dark and light phases. In the case of saccharin preference, we tested this correlation using values from a single day. Because saccharin consumption was measured every $24 \mathrm{~h}$ over several days, LD22 rat data are divided into aligned and misaligned at the end of the experiment by compiling days of alignment or days of misalignment for each animal. Tukey's post hoc test was used for pairwise multiple comparisons when groups or the interaction were found statistically different. All statistical tests were done with $\mathrm{R}$ version 3.1.2 using 'nlme,' 'R.matlab,' and 'survival' packages.

\section{Results}

\section{Body mass and locomotor activity}

Body mass of control rats $(372.75 \pm 15.19 \mathrm{~g}, n=22)$ did not significantly differ from that of desynchronized rats (382.17 $\pm 10.36 \mathrm{~g}, n=47$; Fig. $2 A ; F_{1,67}=3.57, p=0.06$ ). As expected, the circadian rhythm of locomotor activity significantly differed between groups and phase of day (Fig. $2 B, C$; interaction effect $F_{2,161}=165.9, p<0.001$ ). Specifically, during the light phase, LD24 control rats had lower locomotor activity $(n=22)$ than LD22 rats during aligned days ( $n=47$; Tukey's post hoc test: $p<0.001$ ), and LD22 misaligned rats had the highest locomotor activity levels ( $n=47$; Tukey's post hoc test: $p<0.001)$. During the dark phase, there was no difference between
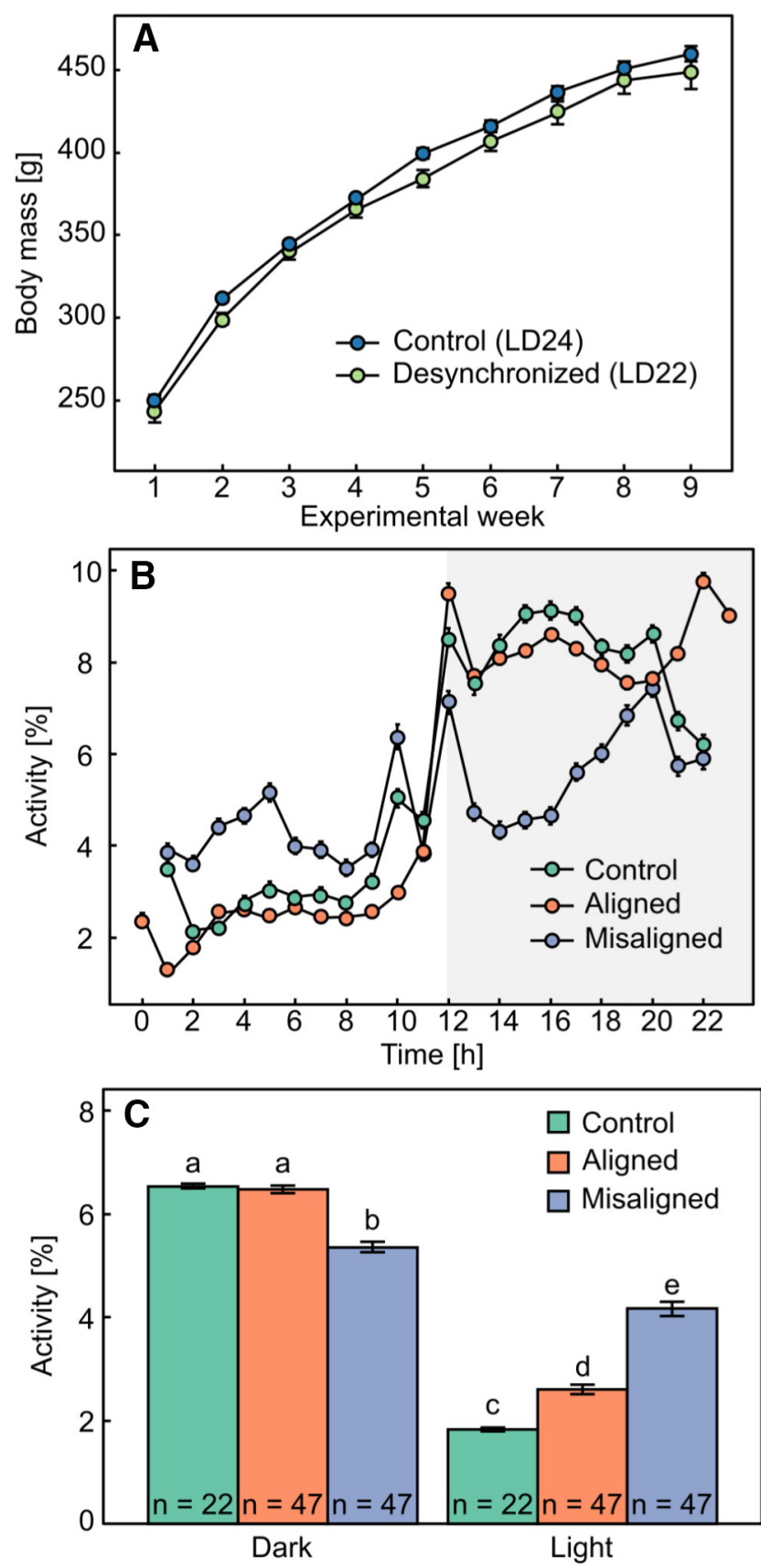

Figure 2. The effect of forced desynchrony on body mass and locomotor activity. $\boldsymbol{A}$, Change in mean \pm SE body mass in LD24 controls $(n=22)$ and LD22 desynchronized $(n=47)$ animals throughout the experiment. $\boldsymbol{B}$, Mean \pm SE locomotor activity [\% of total activity during each 24- or 22-h cycle] of LD24 control rats and LD22 desynchronized rats. Shaded gray area denotes lights off. Note that data for desynchronized animals corresponds to $11 \mathrm{~h}$ of light and $11 \mathrm{~h}$ of darkness. C, Mean \pm SE locomotor activity per hour (total IR beam interruptions) averaged over either the light or dark phase for control rats, aligned rats, and misaligned rats. Different letters denote statistically significant differences between groups.

locomotor activity levels of LD24 control rats $(n=22)$ and LD22 aligned rats ( $n=47$; Tukey's post hoc test: $p=0.9$ ), but LD22 misaligned rats had significantly lower levels of 
locomotor activity ( $n=47$; Tukey's post hoc test: $p<$ $0.001)$. Finally, the amplitude of locomotor activity was significantly different between groups $\left(F_{2,46}=130.5, p<\right.$ 0.001 ), where LD24 control rats had the highest amplitude of locomotor activity, and LD22 misaligned rats had the lowest amplitude compared with both LD22 aligned rats and LD24 control rats.

\section{Circadian forced desynchrony and behavioral performance}

Saccharin preference test

We did not find a difference in saccharin preference throughout the 8 days of the test $\left(F_{1,257}=2.38, p=0.1\right)$. This allowed us to consolidate data of LD22 desynchronized rats measured on different days, as alignment and misalignment days did not fall on the same date for each individual. LD24 control rats consumed a significantly larger fraction of $0.1 \%$ saccharin $(0.76 \pm 0.02, n=22)$ than LD22 rats measured during aligned days (0.65 \pm $0.03, n=47$; Fig. $3 A ; D=0.19, p=0.03$ ), but not more than LD22 rats measured during misaligned days $(0.69 \pm$ $0.04, n=47 ; D=0.15, p=0.6)$. Saccharin consumption did not differ between rats measured during aligned and misaligned days (Fig. $3 A ; D=0.14, p=0.5$ ).

\section{Open field test}

No differences were found between treatment groups in the fraction of time rats spent in the perimeter of the open field test arena (Fig. $3 B$; group: $F_{2,25}=2.52, p=0.1$; group $\times$ phase interaction: $F_{2,25}=0.86, p=0.4$ ), and there was no difference in preference for the perimeter between the light and the dark phases (Fig. 3B; phase: $\left.F_{1,25}=0.12, p=0.7\right)$. In addition, no differences were found in the distance travelled by the rats (group: $F_{2,25}=$ $1.49, p=0.2$, group $\times$ phase interaction: $F_{1,25}=0.46, p$ $=0.6$ ), but the distance travelled by all rats during the dark phase was greater than the distance travelled by all rats during the light phase (phase: $F_{1,25}=18.12, p<$ 0.001).

\section{Forced swim test}

Immobility time during the FST was significantly different between treatment groups (Fig. $3 C ; F_{2,34}=8.42, p=$ 0.001). Specifically, during the dark phase, LD24 control rats showed significantly lower immobility time than LD22 aligned (Tukey's post hoc test: $p=0.02$ ) and misaligned (Tukey's post hoc test: $p=0.02$ ) rats. During the light phase, LD24 rats had significantly higher immobility time than LD22 aligned (Tukey's post hoc test: $p=0.01$ ) and misaligned (Tukey's post hoc test: $p=0.05$ ) rats.

\section{Sexual behavior test}

Circadian forced desynchrony had an effect on sexual behavior. During the dark phase (Fig. $4 A ; \chi^{2}=7.83, p=$ 0.02) LD24 control rats $(n=11)$ had a shorter mounting latency than both aligned ( $n=11$; Tukey's post hoc test: $p=0.01)$ and misaligned ( $n=12$; Tukey's post hoc test: $p=0.003$ ) rats, but no such differences were found in the light phase $\left(\chi^{2}=2.46, p=0.3\right)$. Similarly, a difference in ejaculation latency was found during the dark phase (Fig. $\left.4 B ; \chi^{2}=7.89, p=0.02\right)$, with LD24 control rats $(n=11)$ having shorter ejaculation latency than LD22 aligned $(n=$
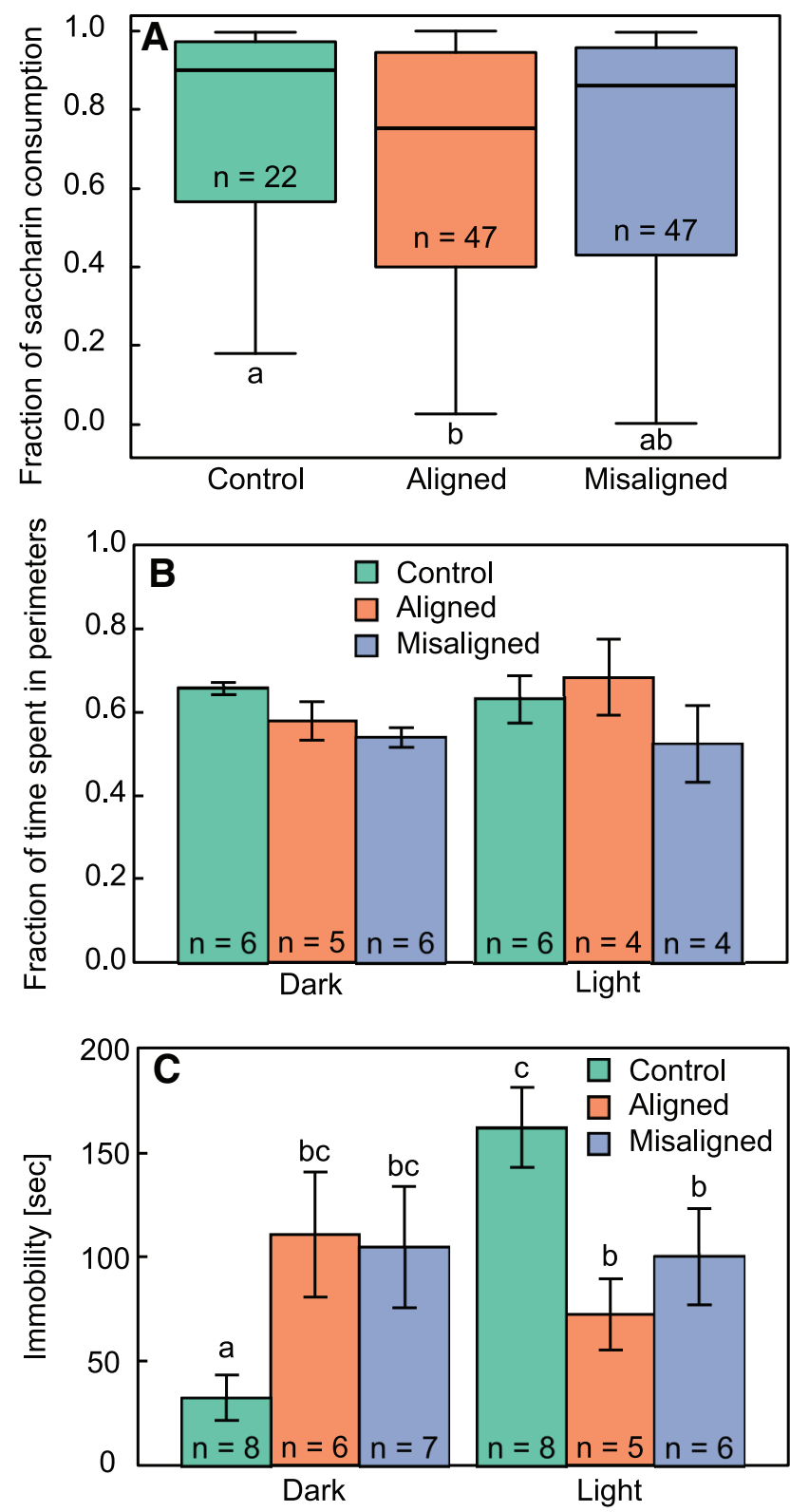

Figure 3. Effect of circadian forced desynchrony on behavioral manifestations of depression. $\boldsymbol{A}$, Fraction of $0.1 \%$ saccharin consumption averaged over $8 \mathrm{~d}$ for LD24 control, LD22 aligned, and LD22 misaligned rats. Boxes outline the lower (25\%) and upper $(75 \%)$ quartiles, and the line denotes the median. Error bars represent the $95 \%$ confidence intervals. Different letters denote statistically significant differences $(p<0.05)$. $\boldsymbol{B}$, Fraction of time spent in the perimeters of the open field test arena, during the light and dark phases in the same groups. $\boldsymbol{C}$, Immobility time during the 5-min FST in the light and dark phases. Different letters denote statistically significant differences $(p<0.05)$. All values represent mean \pm SE.

11 ; Tukey's post hoc test: $p=0.02$ ) but not misaligned ( $n$ $=12$; Tukey's post hoc test: $p=0.06$ ) rats. When we included mean locomotor activity as a covariate, we found that it had a significant effect on ejaculation latency $\left(F_{1,56}\right.$ $=4.20, p=0.05)$, but this effect did not alter the results because the effect of group remained significant $\left(F_{2,56}=\right.$ 

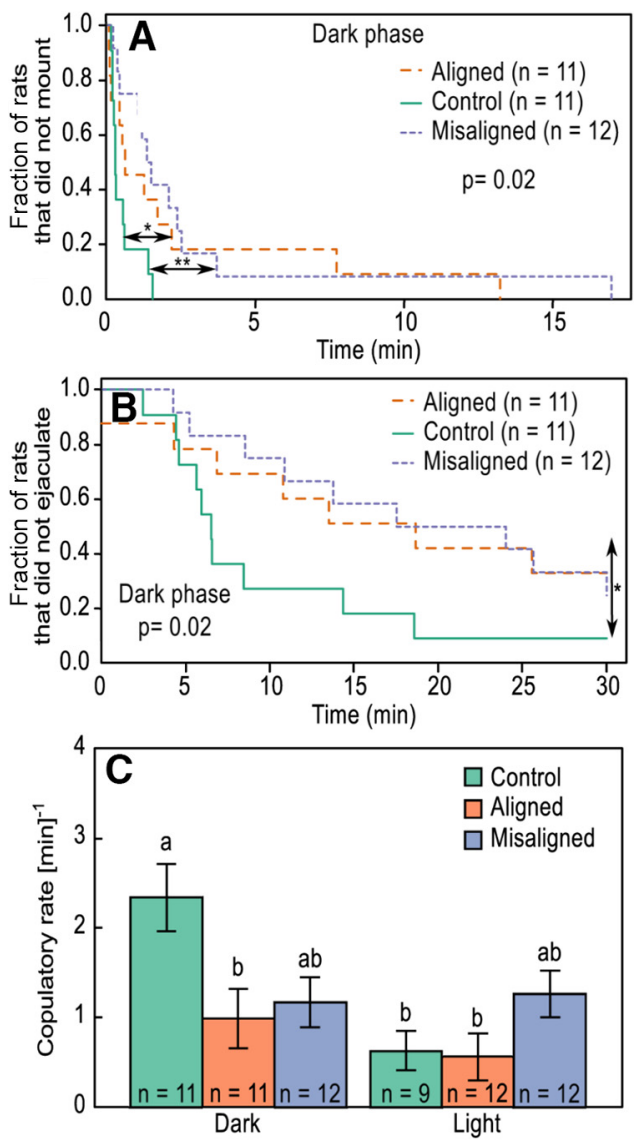

Figure 4. Effect of circadian forced desynchrony on sexual behavior of male rats during the dark phase. Percentage of LD24 control and LD22 desynchronized male rats that did not mount $(\boldsymbol{A})$ and did not ejaculate $(\boldsymbol{B})$ as a function of the time lapsed from the introduction of a receptive female. $* p<0.05, * * p<0.01$. Log-rank values were calculated based on a Kaplan-Meier survival analysis. $\boldsymbol{C}$, Mean \pm SE copulatory rate in LD24 control and LD22 desynchronized males. Copulatory rate was calculated as the sum of mounting and intromission events divided by the time lapsed from the first mounting event until the first ejaculation event. Different letters denote statistical differences between groups $(p<0.05)$.

$4.85, p=0.01$ ). No differences in ejaculation latency were found during the light phase $\left(\chi^{2}=3.70, p=0.2\right)$. Furthermore, no difference was found in intromission latency during the light $\left(\chi^{2}=2.79, p=0.3\right)$ or dark $\left(\chi^{2}=2.11, p\right.$ $=0.3$ ) phases. Finally, LD22 aligned rats had lower copulatory rates than LD24 control rats during the dark phase (Fig. $4 C ; F_{2,62}=4.71, p=0.01$ ), whereas misaligned rats did not differ from aligned (Tukey's post hoc test: $p=1.0$ ) or LD24 control (Tukey's post hoc test: $p=0.07$ ) rats. Mean locomotor activity had a significant effect on copulatory rate $\left(F_{1,56}=9.65, p=0.003\right)$, but even when this effect was included in the model, we found a significant effect of group $\left(F_{2,56}=3.63, p=0.03\right)$.

Because females were tested at different time points during their 24-h cycle, we included the female ZT as a covariate in our analysis. We found no effect of the female ZT on either ejaculation latency $\left(F_{1,66}=2.39, p=0.1\right)$ or mounting latency $\left(F_{1,66}=1.51, p=0.2\right)$. We did find a significant effect of the female $\mathrm{ZT}$ on copulatory rate $\left(F_{1,66}\right.$ $=3.99, p=0.05)$. However, when accounting for this effect, we still found a significant difference between groups (group: $F_{2,56}=3.49, p=0.04$; group $\times$ phase interaction: $F_{2,56}=4.30, p=0.02$ ), with LD24 control rats showing higher copulatory rate during the dark phase compared with LD22 aligned rats (Tukey's post hoc test: $p=0.05$ ), but not compared with LD22 misaligned rats (Tukey's post hoc test: $p=0.1$ ). Copulatory rate of LD22 misaligned rats was also not statistically different from that of LD22 aligned rats (Tukey's post hoc test: $p=0.99$ ). Thus, the effects were identical to those we report above.

\section{Depression score}

We found a significant difference between scores of different groups (Fig. $5 A ; \chi^{2}{ }_{(2)}=7.63, p=0.02$ ). Specifically, the depression score of control rats $(-0.43 \pm 0.27)$ was significantly lower than that of LD22 aligned $(0.89 \pm$ 0.45 ; post hoc test: $p=0.03$ ) as well as LD22 misaligned $(0.84 \pm 0.42$; post hoc test: $p=0.03)$ rats.

\section{Correlations between amplitude of locomotor activity} and performance in the behavioral tests

The fraction of $0.1 \%$ saccharin consumption over a period of $24 \mathrm{~h}$ was positively correlated with the amplitude of locomotor activity during the day of the test (Fig. 5B; $\left.F_{1,69}=10.17, p=0.002, R^{2}=0.13\right)$. Additionally, both latency to mounting (Fig. $5 C ; F_{1,33}=18.29, p<0.001, R^{2}$ $=0.36$ ) and latency to ejaculation (Fig. $5 D ; F_{1,25}=6.29, p$ $=0.02, R^{2}=0.20$ ) in the dark phase were negatively correlated with the amplitude of locomotor activity during the day of the test. Finally, we found a significant positive correlation between immobility in the FST and the amplitude of locomotor activity during the day of the test (Fig. $\left.5 E ; F_{1,7}=5.60, p=0.05, R^{2}=0.44\right)$.

\section{Circadian forced desynchrony and prefrontal cortex monoamine levels and turnover}

We analyzed the amount of NE, DA, and 5-HT and their respective metabolites in the PFC at the same phases in which behavioral tests were performed in LD24 and LD22 aligned animals (Fig. 6). Table 1 shows monoamine and metabolite levels, their calculated turnover, and statistical results. NE (Fig. $6 A ; \mathrm{F}_{1,28}=4.49, p=0.04$ ) and DA (Fig. $6 B ; F_{1,28}=10.21, p=0.003$ ) levels were higher in LD22 desynchronized rats compared with LD 24 controls $(25 \%$ and $48 \%$, respectively), and neither group showed a circadian oscillation in NE (Fig. $6 A ; F_{1,28}=1.10, p=0.3$ ) or DA (Fig. $6 B ; F_{1,28}=2.00, p=0.2$ ) levels. 5 -HT levels were higher during the dark than during the light phase in both groups (Fig. $6 C ; F_{115}=4.60, p=0.05$ ), and there were no differences in 5-HT levels between LD24 controls and LD22 desynchronized rats (Fig. $6 C ; F_{1,15}=0.24, p=0.6$ ). Finally, there were no differences in turnover rates of $\mathrm{NE}$ (Fig. $6 A^{\prime} ; F_{1,28}=0.89, p=0.4$ ) or DA (Fig. $6 B^{\prime} ; F_{1,28}=$ $0.0006, p=0.98$ ) between groups, but the turnover rate of 5 -HT was significantly higher in LD22 desynchronized rats than in LD 24 controls (Fig. $6 C^{\prime} ; F_{1,15}=12.80, p=0.003$ ).

\section{Discussion}

The link between affective disorders and disruptions of the circadian system has been recognized for decades 

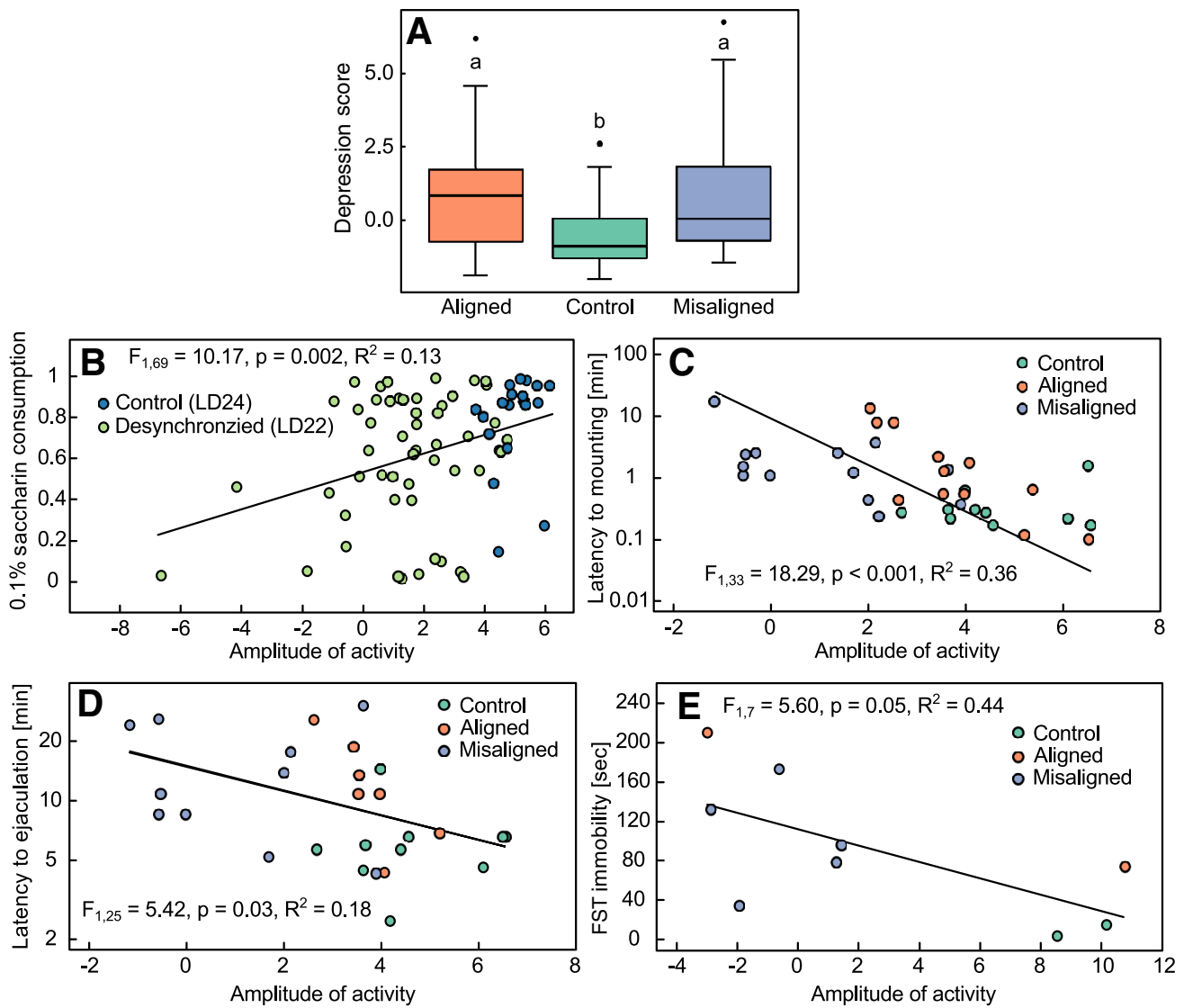

Figure 5. The effect of circadian forced desynchrony on behavioral performance. $\boldsymbol{A}, \mathrm{A}$ depression score (higher values indicate a depressive phenotype) for LD24 control, LD22 aligned, and LD22 misaligned rats. Boxes outline the lower (25\%) and upper (75\%) quartiles, and the line denotes the median. Error bars represent the 95\% confidence intervals, and the black circles are outliers. Different letters denote statistically significant differences $(p<0.05)$. The amplitude of circadian locomotor activity predicts the severity of behavioral manifestations of depression. B. Fraction of $0.1 \%$ saccharin consumption over a $24-\mathrm{h}$ period in LD24 control and LD22 desynchronized animals as a function of the amplitude of locomotor activity on the day of the test. Latency to mounting $(\boldsymbol{C})$ and ejaculation $(\boldsymbol{D})$ during the dark phase as a function of the amplitude of locomotor activity on the day of the test. $\boldsymbol{E}$, Immobility in the FST during the dark phase as a function of the amplitude of locomotor activity on the day of the test, calculated as the difference between the mean activity per hour during the dark phase and the mean activity per hour during the light phase.

(Wulff et al., 2010; McClung, 2013). Nevertheless, it is unclear whether circadian disorders may represent a comorbidity of mental disease or, alternatively, challenges to circadian organization may be among the prevalent factors that increase susceptibility to mood disorders. Our results show that long-term desynchronization of the circadian system in a neurally, genetically, and pharmacologically intact mammal leads to depressivelike behavior, as indicated by increased immobility in the FST and decreased hedonic behavior in the SPT and SBT (Figs. 3 and 4). Moreover, we found that the severity of the circadian desynchronization, as estimated by the amplitude of locomotor activity, was correlated with performance in the behavioral tests (Fig. 5). Specifically, the lower the amplitude of locomotor activity rhythm, the stronger the depressive phenotype was on the behavioral tests. These results suggest that internal circadian desynchronization contributes to the pathogenesis of affective disorders.

The manipulation of the LD cycle in the forced desynchronized rat leads to the desynchronization of circadian rhythms, including the rhythms of core body temperature, release of corticosterone and melatonin, and REM sleep (de la Iglesia et al., 2004; Cambras et al., 2007; Lee et al., 2009; Schwartz et al., 2009; Wotus et al., 2013). The internal misalignment of these circadian rhythms is characteristic of depression in humans as well (Souêtre et al., 1989; Riemann et al., 2001; Lewy, 2009). This misalignment is in agreement with the pattern of clock gene expression in extra-SCN neural circadian oscillators in postmortem tissue from human patients with depression and in animal models of depression (Li et al., 2013; Landgraf et al., 2015; Logan et al., 2015; Savalli et al., 2015). However, depression in the animal models used in these studies was induced by aversive methods, and the causality between desynchronization and the manifestation of depression could not be established. In the forced desynchronized rat, the simple manipulation of the LD cycle causes the predictable and stable desynchronization of neuronal oscillators within the SCN in the absence of any invasive intervention, and this in turn leads to a depressive behavioral phenotype. 

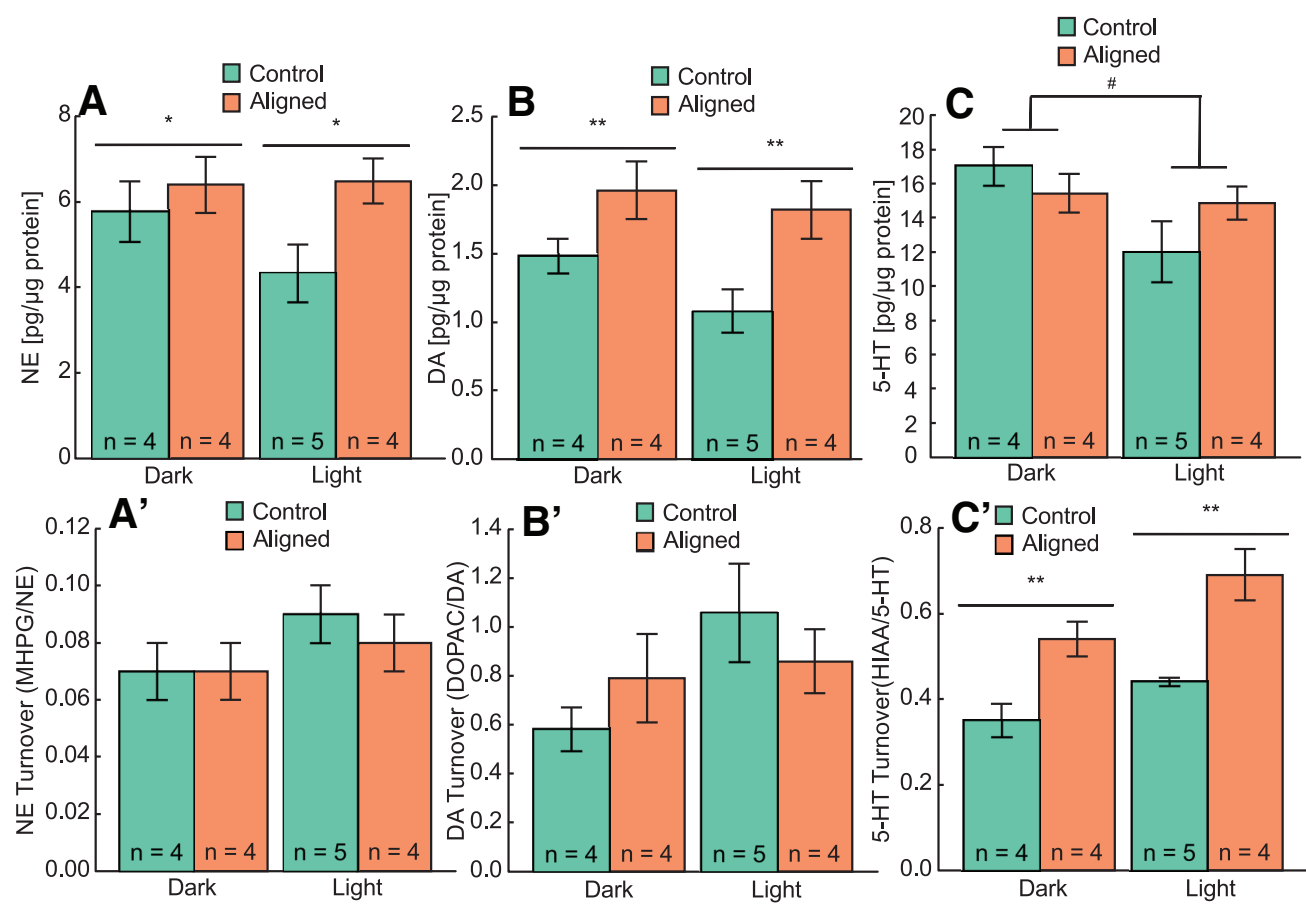

Figure 6. Forced desynchronized rats show a significant increase of levels of NE and DA and of 5-HT turnover in the prefrontal cortex. $\boldsymbol{A}-\boldsymbol{C}$, Mean \pm SE levels of each monoamine. $\boldsymbol{A}^{\prime}-\boldsymbol{C}^{\prime} ;$ mean \pm SE turnover for each monoamine. $* p<0.05$, $* * p<0.01$ (group effect); $\# p=0.05$ (phase effect). See Table 1 for statistics.

For the present study, we used a single-exposure FST that has been previously validated in an animal model of light deprivation-induced depression. Rats kept for 6 weeks in constant darkness showed increased immobility in the first 5 min of exposure to the test compared with controls, and this behavioral deficit was reversed by desipramine (Gonzalez and Aston-Jones, 2008). Similarly, desynchronized rats during the dark phase in our study showed a spontaneous despair behavior revealed by the increased immobility during the 5-min FST, an expected outcome if circadian desynchrony predisposes individuals to a behavioral depressive phenotype. Importantly, the FST depressive phenotype observed in aligned LD22 animals during the dark phase, compared with LD24 animals during the same phase, cannot be attributed to reduced locomotor activity because the activity in the home cage for these groups did not differ (Fig. 2B, C).
We argue that this reduced response-increased immobility-to helplessness during a time of the day at which the animals are expected to be more active represents a phenotypic manifestation of depression.

Control rats kept under LD24, showed a daily (likely circadian) modulation of performance in the FST, manifested as less immobility during the dark phase. This modulation has been largely ignored in studies using behavioral markers of depression, which typically perform the tests during the rest (light) phase of the animals. Indeed, Tataroğlu et al. (2004) have shown that bilateral lesion of the SCN in rats leads to reduced behavioral despair, and suggested that the lesion had an ameliorative effect on the strategy to respond to the stress of the FST. Because the animals in that study were tested during the light phase, an alternative explanation that we favor for this result is that the lesions do not reduce

Table 1. Monoamine levels in PFC of LD24 controls and LD22 aligned desynchronized rats.

\begin{tabular}{|c|c|c|c|c|c|c|c|}
\hline & \multicolumn{2}{|c|}{ LD24 } & \multicolumn{2}{|c|}{ LD22 } & \multicolumn{3}{|c|}{ Two-way ANOVA } \\
\hline $\begin{array}{l}\text { Substance } \\
\text { Monoamine (pg/ } \mu \mathrm{g} \text { protein) }\end{array}$ & Light & Dark & Light & Dark & Group & Phase & Interaction \\
\hline NE & $4.33 \pm 0.67$ & $5.78 \pm 0.70$ & $6.48 \pm 0.53$ & $6.39 \pm 0.66$ & $F_{1,28}=4.49 ; p=0.04$ & $F_{1,28}=1.10 ; p=0.3$ & $F_{1,28}=1.39 ; p=0.2$ \\
\hline DA & $1.08 \pm 0.16$ & $1.48 \pm 0.13$ & $1.82 \pm 0.21$ & $1.96 \pm 0.21$ & $F_{1,28}=10.21 ; p=0.003$ & $F_{1,28}=2.00 ; p=0.2$ & $F_{1,28}=0.44 ; p=0.5$ \\
\hline $\begin{array}{l}5-\mathrm{HT} \\
\text { Metabolite (pg/ } \mu \mathrm{g} \text { protein) }\end{array}$ & $12.00 \pm 1.79$ & $17.00 \pm 1.13$ & $14.86 \pm 0.96$ & $15.40 \pm 1.13$ & $F_{1,15}=0.24 ; p=0.6$ & $F_{1,15}=4.60 ; p=0.05$ & $F_{1,15}=2.97 ; p=0.1$ \\
\hline MHPG & $0.39 \pm 0.06$ & $0.37 \pm 0.03$ & $0.48 \pm 0.03$ & $0.41 \pm 0.04$ & $F_{1,28}=3.03 ; p=0.09$ & $F_{1,28}=1.17 ; p=0.3$ & $F_{1,28}=0.38 ; p=0.5$ \\
\hline DOPAC & $1.12 \pm 0.23$ & $0.89 \pm 0.14$ & $1.41 \pm 0.14$ & $1.19 \pm 0.30$ & $F_{1,27}^{1, \angle 0}=2.34 ; p=0.1$ & $F_{1,27}^{1, \angle 0}=1.43 ; p=0.2$ & $F_{1,27}^{1, \angle 0}=0.01 ; p=0.9$ \\
\hline $\begin{array}{l}\text { HIAA } \\
\text { Turnover }\end{array}$ & $5.25 \pm 0.15$ & $5.82 \pm 0.50$ & $10.26 \pm 1.24$ & $8.22 \pm 0.49$ & $F_{1,15}=10.52 ; p=0.006$ & $F_{1,15}=0.41 ; p=0.5$ & $F_{1,15}=1.30 ; p=0.3$ \\
\hline NE (MHPG/NE) & $0.09 \pm 0.01$ & 0.070 .01 & $0.08 \pm 0.01$ & $0.07 \pm 0.01$ & $F_{1,28}=0.89 ; p=0.4$ & $F_{1,28}=3.36 ; p=0.08$ & $F_{1,28}=1.53 ; p=0.2$ \\
\hline DA (DOPAC/DA) & $1.06 \pm 0.20$ & $0.58 \pm 0.09$ & $0.86 \pm 0.13$ & $0.79 \pm 0.18$ & $F_{1,28}=0.0006 ; p=0.98$ & $F_{1,28}=3.12 ; p=0.09$ & $F_{1,28}=0.20 ; p=0.2$ \\
\hline $5 \mathrm{HT}(\mathrm{HIAA} / 5 \mathrm{HT})$ & $0.44 \pm 0.01$ & $0.35 \pm 0.04$ & $0.69 \pm 0.06$ & $0.54 \pm 0.04$ & $F_{1,15}=12.80 ; p=0.003$ & $F_{1,15}=3.96 ; p=0.07$ & $F_{1,15}=0.22 ; p=0.6$ \\
\hline
\end{tabular}

Levels (pg/ $\mu \mathrm{g}$ of protein) of monoamines and their metabolites are shown as mean \pm SE. Turnover is shown as the ratio of each metabolite over each respective monoamine. The main effects of the two-way ANOVA are shown. Values in bold are significant. 
despair but instead eliminate the circadian modulation of the FST performance.

In contrast to LD24 rats, LD22 animals did not show similar circadian modulation of FST performance, as evident from the lack of differences in levels of immobility between the dark and light phases. Specifically, rats tested during both aligned and misaligned days showed higher immobility during the dark phase and lower immobility during the light phase compared to controls. Because mood was shown to oscillate daily in humans from different cultures around the globe (Golder and Macy, 2011) and a blunted rhythm of mood during the $24 \mathrm{~h}$ day was found in depressive patients (Boivin, 2000; WirzJustice, 2006), we suggest that LD22 aligned rats show attenuated rhythm of immobility in the FST, characterized by respectively lower and higher immobility during the light and dark phases than controls, and no difference in levels of immobility between the two phases.

Strikingly, we found that LD22 desynchronized rats displayed lower levels of immobility during the light phase than LD24 control rats (Fig. $3 C$ ). We do not think that this is an indication of manic behavior for two reasons. First, LD22 rats consistently display anhedonia in the other behavioral tests. Second, because misaligned animals are tested in conflicting phases-subjective day during the dark phase or subjective night during the light phasetheir immobility in the FST could reflect the opposing effects of light and the circadian system on escape performance rather than the depressive state of the animal. In line with this interpretation, immobility in LD22 misaligned animals during the light phase was higher than immobility in LD24 animals during the dark phase but lower than immobility in in LD24 animals during the light phase.

Our study is the first to show that internal circadian desynchronization leads to sexual dysfunction. We found that circadian desynchronization affects both sexual motivation, estimated by the latency to mount (Pfaus et al., 1990), and sexual function, estimated by the latency to and occurrence of ejaculation (Ågmo, 1997). Moreover, the severity of the circadian disturbance, i.e., the reduction in amplitude of locomotor activity during the day of the test, was correlated with both measures (Fig. 5C, D), suggesting that the impairment of sexual behavior is linked to the extent of circadian disruption. The prevalence of sexual dysfunction in depressive patients not treated with antidepressants is estimated to be $50-60 \%$, but this value is likely to be an underestimation because sexual inquiry is often not included in the medical assessment (Kennedy et al., 1999; Bonierbale and Tignol, 2003; Basson and Schultz, 2007). Our results suggest that circadian desynchronization may be a contributing factor to both negative affect and sexual dysfunction. Of note, sexual dysfunction has not been previously tested in animal models of depression, and our results show that it represents a sensitive behavioral outcome to assess the depressive phenotype of an animal, one that is more meaningful than other metrics for both its ecophysiological and translational value. Specifically, the FST has been criticized as a behavioral assessment for depression because (1) it is heavily dependent on locomotor activity performance (Slattery and Cryan, 2012) and (2) as a method to induce depression, it represents an unusually stressful situation that bears little relationship to depression triggers in humans (Holmes, 2003). In the present study, we did not use the FST to induce depression but rather as a probe test to assess a preexisting depressive state. Nevertheless, it still can be argued that a test in which an individual has to swim after being placed in an unescapable pool of water is unlike most stressful situations that lead to a manifestation of depression in humans. In this context, we propose that assessing sexual performance may represent a more sensitive and meaningful testing approach in animal models of depression.

The depressive-like phenotype we found was independent of levels of anxiety, as evident from the lack of differences between desynchronized and control preference for the perimeter of the arena in the OFT (Fig. 3B). Although there is a strong comorbidity between anxiety disorders and depression, they are still considered independent disorders. This suggests that the desynchronized rat may serve as a model for exploring depressive behavior independently of anxiety, although further tests of anxiety level are required to confirm this finding.

The correlation between abnormal light exposure, disrupted rhythms, and mood disorders suggests that photic stimulation of the circadian system through the RHT is critical for the maintenance of mood. This mechanism could explain seasonal affective disorder (SAD), a form of depression linked to the short winter photoperiod that is responsive to bright light therapy (Golden et al., 2005). The circadian basis of light therapy-induced improvement in mood in SAD patients is supported by the fact that light appears to be more beneficial when applied at a specific circadian phase: for some patients morning treatment is efficacious, and for others, evening treatment (Terman and Terman, 2005). Furthermore, light therapy is beneficial not only in SAD but in virtually all forms of depression, suggesting that circadian pathologies could contribute to the etiology of depression in general (Pail et al., 2011). Remarkably, nocturnal rats present an anatomical and behavioral depressive phenotype after weeks of exposure to total darkness. The absence of light alone reduces the amplitude of the SCN-dependent sleep-wake circadian rhythm and generates neural damage in monoamine brain systems that are SCN-transynaptic targets, in association with a depressive behavioral phenotype (Gonzalez and Aston-Jones, 2006, 2008). Interestingly, Dulcis et al. (2013) showed that the type of neurotransmitter released from nuclei receiving direct SCN input is dependent on photoperiod length, and that the alteration in neurotransmitter release is associated with a depressive-like behavior in mice. Forced desynchronized rats, however, are not exposed to different amounts of light, as the LD22 schedule results in the same proportion of light and dark as an LD24 schedule. Thus, the depressive behavioral phenotype of forced desynchronized rats likely emerges from the stable desynchrony between the vl- and dmSCN. This appears to differ from the depressive phenotype that emerges in mice exposed to aberrant LD cycles of $7 \mathrm{~h}$ (3.5L:3.5D), in which the SCN appears not to be affected 
by the schedule and the phenotype has been proposed to be mediated by retinal innervation of limbic regions (LeGates et al., 2012, 2014).

The monoamine hypothesis of depression postulates that the pathogenesis of depression involves impairment of $5-\mathrm{HT}, \mathrm{NE}$, and DA systems in the central nervous system (Delgado, 2000; Hirschfeld, 2000), and there is evidence that these abnormalities are localized to the PFC and the limbic system (Drevets, 1999). Our desynchrony protocol leads to an imbalance in the regulation of monoamine levels and their release in the PFC, which is manifested as higher levels of NE and DA and higher 5-HT turnover rate (Fig. 6). The role of DA in depression is still not well understood and is challenged by the paradoxical antidepressant effect of both agonists and antagonists of DA (Dailly et al., 2004). In stressed rats, there is increased release of NE and DA in the PFC, and chronic mild stress causes an increase in the magnitude of this response (Finlay et al., 1995; Di Chiara et al., 1999). It is therefore possible that the higher levels of NE and DA we found in the PFC of LD22 desynchronized rats result from stress sensitization of these individuals, as brain tissue of these rats was collected immediately after an OFT. In contrast, we found unchanged 5-HT levels combined with higher 5-HT turnover rate in LD22 desynchronized rats, suggesting that these animals have a lower availability of 5-HT, which could account for their depressive like behavior. This is also consistent with decreased availability of $5-\mathrm{HT}$ in patients with SAD and the $24 \%$ decrease in serotonergic axons found in the PFC of suicide victims (Austin et al., 2002). Our findings provide a direct link between stable circadian desynchronization and an imbalance in monoamine regulation in the PFC. Obviously, the PFC is not the only brain region involved in the modulation of motivational states, and changes in other transmitter systems, as well as in intracellular regulatory pathways within or outside the PFC, could underlie the expression of depressive behaviors in the forced desynchronized rat.

In summary, our study shows that the stable forced desynchrony of circadian rhythms leads to the manifestation of a depressive-like phenotype. This phenotype likely emerges from the desynchronization of neuronal oscillators within the $\mathrm{SCN}$ and is associated with the severity of circadian desynchronization and an imbalance in monoamine metabolism within the PFC. Taken together, our findings provide direct support for a circadian desynchronization etiology of depressive behavior. Hence, the forced desynchronized rat could represent a unique neurologically, pharmacologically, and genetically intact animal model to study the neural basis of affective disorders and its relationship with internal circadian misalignment.

Note added in proof: The affiliation of several authors were incorrect and funding sources not included on the article published on-line December 5, 2016, as an Early Release. The affiliations list has since been corrected and the funding sources "Geriatric Research, Education and Clinical Center, and the Research and Development Service of the VA Puget Sound Health Care System" were added.

\section{References}

Ågmo A (1997) Male rat sexual behavior. Brain Res Protocols 1:203209. CrossRef

Aston-Jones G, Chen S, Zhu Y, Oshinsky ML (2001) A neural circuit for circadian regulation of arousal. Nat Neurosci 4:732-738. CrossRef Medline

Austin M, Whitehead R, Edgar C, Janosky J, Lewis D (2002) Localized decrease in serotonin transporter-immunoreactive axons in the prefrontal cortex of depressed subjects committing suicide. Neuroscience 114:807-815. Medline

Basson R, Schultz WW (2007) Sexual sequelae of general medical disorders. Lancet 369:409-424. CrossRef Medline

Boivin DB (2000) Influence of sleep-wake and circadian rhythm disturbances in psychiatric disorders. J Psychiatr Neurosci 25: 446-458. Medline

Bonierbale M, Tignol J (2003) The ELIXIR study: evaluation of sexual dysfunction in 4557 depressed patients in France. Curr Med Res Opin 19:114-124. CrossRef

Cambras T, Weller JR, Angles-Pujoras M, Lee ML, Christopher A, Diez-Noguera A, Krueger JM, de la Iglesia HO (2007) Circadian desynchronization of core body temperature and sleep stages in the rat. Proc Natl Acad Sci U S A 104:7634-7639. CrossRef

Colwell CS (2011) Linking neural activity and molecular oscillations in the SCN. Nature Reviews Neuroscience 12:553-569. CrossRef Medline

Dailly E, Chenu F, Renard CE, Bourin M (2004) Dopamine, depression and antidepressants. Fund Clin Pharmacol 18:601-607. CrossRef Medline

de la Iglesia HO, Cambras T, Schwartz WJ, Diez-Noguera A (2004) Forced desynchronization of dual circadian oscillators within the rat suprachiasmatic nucleus. Curr Biol 14:796-800. CrossRef Medline

Delgado PL (2000) Depression: the case for a monoamine deficiency. J Clin Psychiatr 61:7-11.

Di Chiara G, Loddo P, Tanda G (1999) Reciprocal changes in prefrontal and limbic dopamine responsiveness to aversive and rewarding stimuli after chronic mild stress: implications for the psychobiology of depression. Biol Psychiatr 46:1624-1633. Medline

Drevets WC (1999) Prefrontal cortical-amygdalar metabolism in major depression. Ann N Y Acad Sci 877:614-637. Medline

Dulcis D, Jamshidi P, Leutgeb S, Spitzer NC (2013) Neurotransmitter switching in the adult brain regulates behavior. Science 340:449453. CrossRef Medline

Finlay J, Zigmond M, Abercrombie E (1995) Increased dopamine and norepinephrine release in medial prefrontal cortex induced by acute and chronic stress: effects of diazepam. Neuroscience 64: 619-628. Medline

Frank E, Kupfer DJ, Thase ME, Mallinger AG, Swartz HA, Fagiolini AM, Grochocinski V, Houck P, Scott J, Thompson W (2005) Twoyear outcomes for interpersonal and social rhythm therapy in individuals with bipolar I disorder. Arch Gen Psychiatr 62:9961004. CrossRef Medline

Golden RN, Gaynes BN, Ekstrom RD, Hamer RM, Jacobsen FM, Suppes T, Wisner KL, Nemeroff CB (2005) The efficacy of light therapy in the treatment of mood disorders: a review and metaanalysis of the evidence. Am J Psychiatr 162:656-662. CrossRef Medline

Golder SA, Macy MW (2011) Diurnal and seasonal mood vary with work, sleep, and daylength across diverse cultures. Science 333: 1878-1881. CrossRef Medline

Golombek DA, Rosenstein RE (2010) Physiology of circadian entrainment. Physiol Rev 90:1063-1102. CrossRef Medline

Gonzalez MMC, Aston-Jones G (2006) Circadian regulation of arousal: role of the noradrenergic locus coeruleus system and light exposure. Sleep 29:1327-1336.

Gonzalez MMC, Aston-Jones G (2008) Light deprivation damages monoamine neurons and produces a depressive behavioral phenotype in rats. Proc Natl Acad Sci U S A 105:4898-4903. CrossRef 
Hemmeter U-M, Hemmeter-Spernal J, Krieg J-C (2010) Sleep deprivation in depression. Expert Rev Neurotherap 10:1101-1115. CrossRef Medline

Hirschfeld RM (2000) History and evolution of the monoamine hypothesis of depression. J Clin Psychiatr 61:4-6. CrossRef

Holmes PV (2003) Rodent models of depression: reexamining validity without anthropomorphic inference. Crit Rev Neurobiol 15:143174. Medline

Keers R, Pedroso I, Breen G, Aitchison KJ, Nolan PM, Cichon S, Nöthen MM, Rietschel M, Schalkwyk LC, Fernandes C (2012) Reduced anxiety and depression-like behaviours in the circadian period mutant mouse afterhours. PLoS One 7:e38263. CrossRef Medline

Kennedy SH, Dickens SE, Eisfeld BS, Bagby RM (1999) Sexual dysfunction before antidepressant therapy in major depression. $J$ Affect Disord 56:201-208. Medline

Landgraf D, Long JE, Welsh DK (2015) Depression-like behaviour in mice is associated with disrupted circadian rhythms in nucleus accumbens and periaqueductal grey. Eur J Neurosci 43:13091320. CrossRef Medline

Landgraf D, Long JE, Proulx CD, Barandas R, Malinow R, Welsh DK (2016) Genetic disruption of circadian rhythms in the suprachiasmatic nucleus causes helplessness, behavioral despair, and anxiety-like behavior in mice. Biol Psychiatr pii: S0006-3223(16)31101-5.

Leak RK, Moore RY (2001) Topographic organization of suprachiasmatic nucleus projection neurons. J Comp Neur 433:312-334. Medline

Lee ML, Swanson BE, de la Iglesia HO (2009) Circadian timing of REM sleep is coupled to an oscillator within the dorsomedial suprachiasmatic nucleus. Curr Biol 19:848-852. CrossRef

LeGates TA, Fernandez DC, Hattar S (2014) Light as a central modulator of circadian rhythms, sleep and affect. Nat Rev Neurosci 15:443-454. CrossRef Medline

LeGates TA, Altimus CM, Wang H, Lee H-K, Yang S, Zhao H, Kirkwood A, Weber ET, Hattar S (2012) Aberrant light directly impairs mood and learning through melanopsin-expressing neurons. Nature 491:594-598. CrossRef Medline

Lewy AJ (2009) Circadian misalignment in mood disturbances. Curr Psychiatr Rep 11:459-465. Medline

Li JZ, Bunney BG, Meng F, Hagenauer MH, Walsh DM, Vawter MP, Evans SJ, Choudary PV, Cartagena P, Barchas JD (2013) Circadian patterns of gene expression in the human brain and disruption in major depressive disorder. Proc Natl Acad Sci U S A 110:99509955. CrossRef

Logan RW, Edgar N, Gillman AG, Hoffman D, Zhu X, McClung CA (2015) Chronic stress induces brain region-specific alterations of molecular rhythms that correlate with depression-like behavior in mice. Biol Psychiatr 78:249-258. CrossRef Medline

Luo AH, Aston-Jones G (2009) Circuit projection from suprachiasmatic nucleus to ventral tegmental area: a novel circadian output pathway. Eur J Neurosci 29:748-760. CrossRef Medline

McCarthy MJ, Welsh DK (2012) Cellular circadian clocks in mood disorders. J Biol Rhythms 27:339-352. CrossRef Medline

McClung CA (2011) Circadian rhythms and mood regulation: insights from pre-clinical models. Eur Neuropsychopharmacol 21:S683S693. CrossRef

McClung CA (2013) How might circadian rhythms control mood? Let me count the ways. Biol Psychiatr 74:242-249. CrossRef Medline

Mohawk JA, Green CB, Takahashi JS (2012) Central and peripheral circadian clocks in mammals. Ann Rev Neurosci 35:445-462. CrossRef Medline

Morris CJ, Yang JN, Scheer FA (2012) The impact of the circadian timing system on cardiovascular and metabolic function. Prog Brain Res 199:337-358. CrossRef Medline

Pail G, Huf W, Pjrek E, Winkler D, Willeit M, Praschak-Rieder N, Kasper S (2011) Bright-light therapy in the treatment of mood disorders. Neuropsychobiology 64:152-162. CrossRef Medline

Patel TP, Gullotti DM, Hernandez P, O'Brien WT, Capehart BP, Morrison IIIB, Bass C, Eberwine JE, Abel T, Meaney DF (2014) An open-source toolbox for automated phenotyping of mice in behavioral tasks. Front Behav Neurosci 8:1-16. CrossRef
Paxinos G, Watson C (1998) The rat atlas in stereotaxic coordinates. New York: Academic.

Pfaus JG, Mendelson SD, Phillips AG (1990) A correlational and factor analysis of anticipatory and consummatory measures of sexual behavior in the male rat. Psychoneuroendocrinology 15: 329-340. Medline

Prendergast BJ, Nelson RJ (2005) Affective responses to changes in day length in Siberian hamsters (Phodopus sungorus). Psychoneuroendocrinology 30:438-452. CrossRef Medline

Prickaerts J, Moechars D, Cryns K, Lenaerts I, van Craenendonck H, Goris I, Daneels G, Bouwknecht JA, Steckler T (2006) Transgenic mice overexpressing glycogen synthase kinase $3 \beta$ : a putative model of hyperactivity and mania. J Neurosci 26:9022-9029. CrossRef Medline

Riemann D, Berger M, Voderholzer U (2001) Sleep and depressionresults from psychobiological studies: an overview. Biol Psychol 57:67-103. Medline

Riemann D, Voderholzer U, Berger M (2002) Sleep and sleep-wake manipulations in bipolar depression. Neuropsychobiology 45:712. CrossRef

Roybal K, Theobold D, Graham A, DiNieri JA, Russo SJ, Krishnan V, Chakravarty S, Peevey J, Oehrlein N, Birnbaum S (2007) Manialike behavior induced by disruption of CLOCK. Proc Natl Acad Sci U S A 104:6406-6411. CrossRef Medline

Saper CB, Lu J, Chou TC, Gooley J (2005) The hypothalamic integrator for circadian rhythms. Trends Neurosci 28:152-157. CrossRef Medline

Savalli G, Diao W, Schulz S, Todtova K, Pollak DD (2015) Diurnal oscillation of amygdala clock gene expression and loss of synchrony in a mouse model of depression. Int $\mathrm{J}$ Neuropsychopharmacol 18:1-11. CrossRef

Schwartz MD, Wotus C, Liu T, Friesen WO, Borjigin J, Oda GA, de la Iglesia HO (2009) Dissociation of circadian and light inhibition of melatonin release through forced desynchronization in the rat. Proc Natl Acad Sci U S A 106:17540-17545. CrossRef

Shioiri T, Kato T, Murashita J, Yamada N, Takahashi S (1993) Changes in the frequency distribution pattern of body weight in patients with major depression. Acta Psychiatr Scand 88:356-360. Medline

Slattery DA, Cryan JF (2012) Using the rat forced swim test to assess antidepressant-like activity in rodents. Nat Protoc 7:1009-1014. CrossRef Medline

Sokolove PG, Bushell WN (1978) The chi square periodogram: its utility for analysis of circadian rhythms. J Theor Biol 72:131-160. Medline

Souêtre E, Salvati E, Belugou J-L, Pringuey D, Candito M, Krebs B, Ardisson J-L, Darcourt G (1989) Circadian rhythms in depression and recovery: evidence for blunted amplitude as the main chronobiological abnormality. Psychiatr Res 28:263-278. Medline

Takahashi JS, Hong H-K, Ko CH, McDearmon EL (2008) The genetics of mammalian circadian order and disorder: implications for physiology and disease. Nat Rev Genet 9:764-775. CrossRef Medline

Tataroğlu Ö, Aksoy A, Yilmaz A, Canbeyli R (2004) Effect of lesioning the suprachiasmatic nuclei on behavioral despair in rats. Brain Res 1001:118-124. CrossRef Medline

Terman M, Terman JS (2005) Light therapy for seasonal and nonseasonal depression: efficacy, protocol, safety, and side effects. CNS Spectrums 10:647-663. Medline

Wirz-Justice A (2006) Biological rhythm disturbances in mood disorders. Int Clin Psychopharmacol 21:S11-S15. CrossRef

Wotus C, Lilley TR, Neal AS, Suleiman NL, Schmuck SC, Smarr BL, Fischer BJ, de la Iglesia HO (2013) Forced desynchrony reveals independent contributions of suprachiasmatic oscillators to the daily plasma corticosterone rhythm in male rats. PLoS One 8:e68793. CrossRef Medline

Wulff K, Gatti S, Wettstein JG, Foster RG (2010) Sleep and circadian rhythm disruption in psychiatric and neurodegenerative disease. Nat Rev Neurosci 11:589-599. CrossRef Medline 